\title{
Scalenus Medius
}

National Cancer Institute

\section{Source}

National Cancer Institute. Scalenus Medius. NCI Thesaurus. Code C52986.

The largest and longest of the three scalene muscles, which attaches to the transverse process of the six lower cervical vertebrae and the first rib, and which functions to bend the cervical part of the vertebral column to the ipsilateral side and to elevate the first rib. 